\title{
Monte Carlo and Analytical Calculation of Lateral Deflection of Proton Beams in Homogeneous Targets
}

\author{
Maurício T. Pazianotto, Guilherme F. Inocente, Danilo Anacleto A. da \\ Silva and Joel M. Hormaza \\ Departamento de Física e Biofísica - Instituto de Biociências \\ Universidade Estadual Paulista "Júlio de Mesquita Filho" - Botucatu - SP, Brasil \\ Distrito de Rubião Júnior $s / n^{\circ}$ \\ 18608-000 Botucatu, SP \\ mpazianotto@gmail.com
}

\begin{abstract}
Proton radiation therapy is a precise form of radiation therapy, but the avoidance of damage to critical normal tissues and the prevention of geographical tumor misses require accurate knowledge of the dose delivered to the patient and the verification of his position demand a precise imaging technique. In proton therapy facilities, the X-ray Computed Tomography (xCT) is the preferred technique for the planning treatment of patients. This situation has been changing nowadays with the development of proton accelerators for health care and the increase in the number of treated patients. In fact, protons could be more efficient than xCT for this task. One essential difficulty in $\mathrm{pCT}$ image reconstruction systems came from the scattering of the protons inside the target due to the numerous small-angle deflections by nuclear Coulomb fields. The purpose of this study is the comparison of an analytical formulation for the determination of beam lateral deflection, based on Molière's theory and Rutherford scattering with Monte Carlo calculations by SRIM 2008 and MCNPX codes.
\end{abstract}

Keywords: Monte Carlo, Protontherapy, Lateral Deflection.

PACS: $87.55 . \mathrm{K}-$

\section{INTRODUCTION}

Proton radiation therapy is a precise form of radiation therapy which employs the favourable depth-dose characteristic of proton Bragg peak [1]. This curve has a relatively low dose entrance in the shallow regions of its path; however near of the end of the proton range, the dose, raises sharply to a peak and falls abruptly to zero [2]. It shape create a region of maximum energy deposition that can be positioned into the target [3]. This implies that proton radiation therapy requires a precise form of imaging technique to predict the position of Bragg peak inside of the patient [4].

Nowadays in several proton therapy facilities, the dose calculation is performed by $\mathrm{X}$-ray computed tomography $(\mathrm{xCT})$ and the patient is positioned with radiography. However the use of xCT images for proton treatment planning ignores the fundamental differences in physical process between proton and photons and is, therefore, potentially inaccurate [5].

Due to the statistical nature of the processes, pCT has some limitation. One of them is the multiple Coulomb scattering (MCS) that reduce the spatial resolution. It is improved 
by the determination of scattering angle the proton leave the material [4]. In this way, the purpose of our study is to compare Monte Carlo calculation of lateral deflection of proton beam with analytical calculation based on Molière's theory [6] and Rutherford scattering [7].

\section{METHODOLOGY}

The calculation was implemented for a proton pencil beam, with energy between 100 and $200 \mathrm{MeV}$. A comparasion was made between Monte Carlo Method and analytical calculations.

\section{Monte Carlo Simulation}

It was calculated the scattering angle of protons that leave the target with two codes: SRIM 2008 [8] and MCNPX v2.5 [9]. The target was homogeneous and filled with water. It was divided into slices of $0.5 \mathrm{~cm}$. The total length was smaller than maximal range of protons in material. The simulation was performed with $5 \cdot 10^{4}$ protons for SRIM 2008 and $1 \cdot 10^{7}$ protons for MCNPX v2.5.

\section{Analytical Calculation}

Two theoretical models were used of analytical calculation: Molière's theory and Rutherford scattering. The Molière's theory considerer scattering through small angles. Most of this deflection is due to Coulomb scattering from nuclei. It was included energy loss too. Rutherford scattering considerer elastic scattering with Coulomb barrier form nuclei without energy loss.

\section{RESULTS AND DISCUSSION}

The figures 1 and 2 shows that scattering angle $v s$ depth for proton beam with energy of $230 \mathrm{MeV}$ and $180 \mathrm{MeV}$. In both the scatter-angle obtained with Molière's theory is smaller than SRIM and Rutherford. It happens because this theory is based on many small-angle scattering. The scatter angle obtained with SRIM shows a non-linear behaviour because it considerer that occur energy loss due to atomic ionization and excitation. For Rutherford model, the behaviour of deflection angle, is approach linear because its energy is constant. In figure 1 the scatter angle for SRIM presents a linear approach. In this case protons do not interacting with the atoms from materials due to its high energy. This behaviour is the same for protons with $180 \mathrm{Mev}$ (figure 2) until $14 \mathrm{~cm}$. After that there is a greater divergence between Rutherford model and SRIM. It occur because the energy loss of protons is bigger, so its interaction with material either.

It's shown in the figure 3 the results of analytical calculation based on Molière Theory. It was used energies in range of 100 to $250 \mathrm{MeV}$. For each one, the angle increases with 


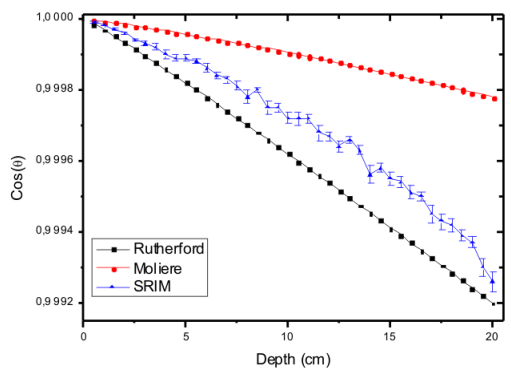

FIGURE 1. Comparation between Monte Carlo and analytical calculation deflection angle. Energy of $230 \mathrm{MeV}$.

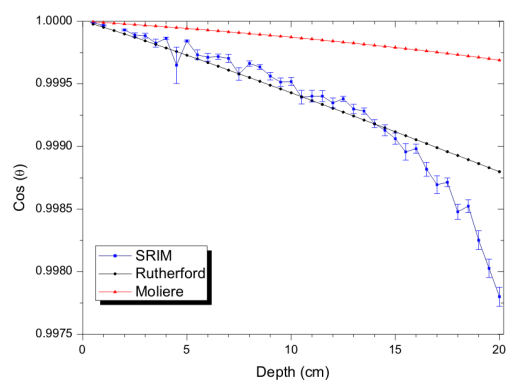

FIGURE 2. Comparation between Monte Carlo and analytical calculation deflection angle. Energy of $180 \mathrm{MeV}$.

depth, but this is minor for higher energies. This occur because at it energy protons interact less with material. It's lead less protons spread and consequently the deflection angle is smaller.

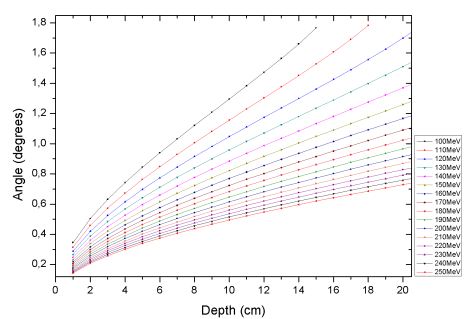

FIGURE 3. Molière calculation of angle of deflection for energy between $100 \mathrm{MeV}$ and $250 \mathrm{MeV}$.

It is presented in figure 4 the deflection angle $v s$ depth for MCNPX. We can see that behaviour of cosine for MCNPX is completely different from graphics previously presented. This is happen because the MCNPX code include inelastic nuclear interaction. 
In this processes when proton has energy above of nucleons bond energy there is the formation of secondary particles (mainly protons). These protons leaves the nuclei in a randomic direction, and it's modify the angular distribution.

When we compare the energies in figure 4, we can see that for higher energies (230 $\mathrm{MeV})$ the formation of secondary particles is greater than for low energies (180 MeV). It leads to an increase of mean scatter-angle. This occur until $14 \mathrm{~cm}$. After that the secondary particles production decreases.

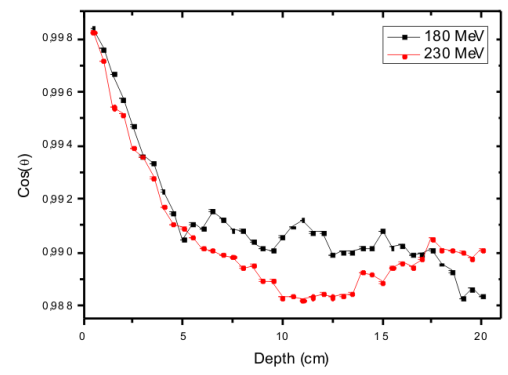

FIGURE 4. Calculation of the cosine of scattering angle with MCNPX for energies of $180 \mathrm{MeV}$ and $230 \mathrm{MeV}$.

\section{REFERENCES}

1. H. F. W. Sadrozinski, V. Bashkirov, M. Bruzzi, L. R. Johnson, B. Keeney, G. Ross, R. W. Schulte, A. Seiden, K. Shahnazi, D. C. Williams, and L. Zhang, Nuclear Instruments and Methods in Physics Research Section A: Accelerators, Spectrometers, Detectors and Associated Equipment 511, 275 - 281 (2003), ISSN 0168-9002, URL http://www.sciencedirect.com/science/article/ B6TJM-48TK66S-C/2/ebdc9a7dcc4a1fdce6427df950eabab2, proceedings of the 11th International Workshop on Vertex Detectors.

2. A. R. Smith, Med Phys 36, 556-568 (2009).

3. T. Bortfeld, H. Paganetti, and H. Kooy, Medical Physics 32, 2048-2049 (2005), URL http:// link.aip.org/link/?MPH/32/2048/3.

4. I. Evseev, M. Klock, S. Paschuk, H. Schelin, J. Setti, R. Lopes, R. Schulte, and W. DC, Brazilian Journal of Physics 34, 804-807 (2004).

5. H.-W. Sadrozinski, V. Bashkirov, B. Keeney, L. Johnson, S. Peggs, G. Ross, T. Satogata, R. Schulte, A. Seiden, K. Shanazi, and D. Williams, Nuclear Science, IEEE Transactions on 51, 3-9 (2004), ISSN 0018-9499.

6. H. A. Bethe, Phys. Rev. 89, 1256-1266 (1953).

7. B. Rossi, and K. Greisen, Rev. Mod. Phys. 13, 240-309 (1941).

8. Particles interactions with matter (2008), URL http: / / www . srim.org/.

9. ed. D. B. Pelowitz, Mcnpx user's manual version 2.5.0, Tech. Rep. Report No. LA-CP-05-0369, Los Alamos National Laboratory, Los Alamos (New Mexico) (2005), sponsored by an agency of the United States Government. 
Copyright of AIP Conference Proceedings is the property of American Institute of Physics and its content may not be copied or emailed to multiple sites or posted to a listserv without the copyright holder's express written permission. However, users may print, download, or email articles for individual use. 